\title{
Imagem \\ Eletrocardiogramas Distintos em Gêmeos Univitelinos com Prolapso Valvar Mitral
}

\author{
Lurildo R. Saraiva, Ana Elizabete M. Batista, Thiago B. Saraiva Leão \\ Recife, PE
}

Avaliados gêmeos univitelinos, sexo masculino, com 10 anos de idade, que compareceram ao Serviço de Cardiologia do Hospital das Clínicas da UFPE, para esclarecimento de sopro cardíaco, verificado nos dois por pediatra. Há oito meses, o gêmeo $\mathrm{A}$, único sintomático, apresentava palpitações freqüentes, mesmo em repouso. No exame clínico cardiovascular do $1^{\circ}$ (gêmeo $A$ ), foram detectados estalido meso-sistólico intenso e sopro sistólico tardio em área mitral; no $2^{\circ}$ (gêmeo B), havia discreto sopro sistólico na mesma área.

O eletrocardiograma do gêmeo A (fig. 1) revelou frequêencia cardíaca de 125 bpm e bloqueio completo de ramo direito, enquanto que no gêmeo $B$, o traçado foi normal (fig. 2). 0 estudo ecodopplercardiográfico detectou espessamento discreto da valva mitral, com prolapso da cúspide anterior no gêmeo A e de ambas

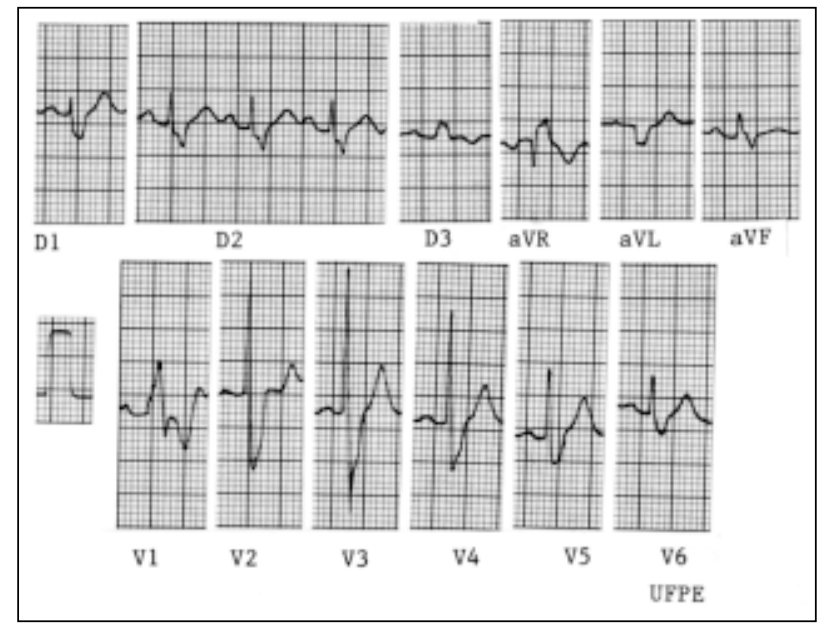

Fig. 1 - Gêmeo A. Eletrocardiograma mostrando taquicardia sinusal e bloqueio completo de ramo direito. as cúspides, no gêmeo $B$; somente no gêmeo $A$, foi registrada regurgitação valvar discreta.

Comentários: Dois ensinamentos emergem deste(s) caso(s): a) a possibilidade de discordância clínico-eletrocardiográfica em gêmeos idênticos, portadores de uma mesma síndrome, muito embora apenas em um deles (A) tenha sido constatada insuficiência mitral; b) o encontro de bloqueio completo de ramo direito nesse mesmo indivíduo, de fato o único enfermo, com ausculta cardíaca mais ruidosa, revelando eventual conexão entre prolapso da valva mitral e distúrbio de condução à direita, sabendo-se que a origem do ramo direito se situa no lado esquerdo do septo interventricular (Moffa PJ, 2002).

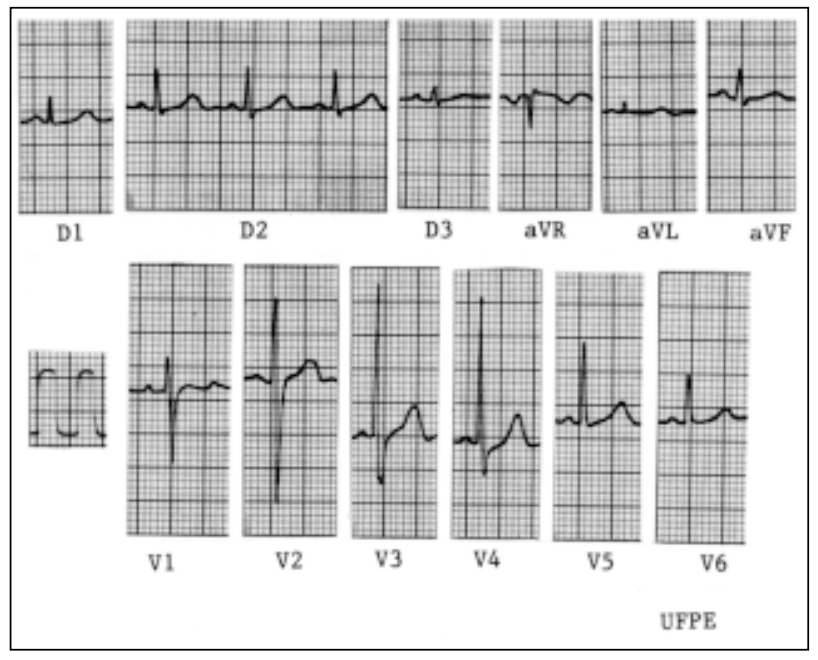

Fig. 2 - Gêmeo B. Traçado eletrocardiográfico normal para a idade. 